\title{
Comparison of the nutritional composition of fresh fruit and fruit-based drinks
}

\author{
Gemma Holland, Fiona McCullough and Gregory Tucker \\ Nottingham University, Nottingham, UK
}

Fruit and vegetables are important components of a healthy balanced diet, especially as sources of antioxidants and polyphenols, yet individuals fail to comply with the recommended five portions daily ${ }^{(1)}$. The demand for 'smoothies' has grown from none to $>£ 20 \times 10^{6}$ over the last 5 years ${ }^{(2)}$. Smoothies are potentially a convenient and palatable way of assisting compliance with the recommended ' 5 -a-day' guideline for fruit and vegetable intake. The aim of the present study was to determine whether nutritional components present in fresh fruit are retained during the production of a fruit-based drink and to elucidate whether a home-made fruit-based drink would be a satisfactory substitute for the commercial smoothie drink.

Pear, apple and kiwifruit (Actinidia delicious), along with the corresponding smoothie (v/v; 45\% pear, $29.6 \%$ apple, $25 \%$ kiwifruit) were collected from a manufacturer. The fruits were analysed individually and these values used to calculate the expected nutritional composition of the final smoothie. Additionally, the fruits were also used to make a home-made fruit-based drink following the smoothie manufacturer's recipe, without the addition of ascorbate. The nutritional composition of the home-made smoothie was then compared with the commercial equivalent. The following nutritional components were determined by established methods: vitamin $\mathrm{C}$ using the Boehringer Mannheim assay ${ }^{(3)}$; antioxidant capacity by the ferric-reducing antioxidant power (FRAP) assay ${ }^{(4)}$ and the oxygen radical absorbance capacity (ORAC) assay ${ }^{(5)}$; polyphenolic content by the Folin-Ciocalteau ${ }^{(6)}$ method. $\beta$-Carotene was measured by extraction into hexane/acetone, absorbance measured and carotene quantified using $\varepsilon_{450 \mathrm{~nm}}=138730 \mathrm{M}^{-1} \cdot \mathrm{cm}^{-1}$. Total sugars were assessed using the D-glucose-fructose-sucrose Boehringer Mannheim assay ${ }^{(3)}$. All assays were carried out in triplicate and statistical analysis was by SPSS (SPSS Inc., Chicago, IL, USA) using an independent $t$ test.

The nutritional composition of pear, apple and kiwifruit extracts and home-made and commercial smoothies are shown in the Table (n 3).

\begin{tabular}{|c|c|c|c|c|c|c|c|c|c|}
\hline & \multicolumn{2}{|c|}{ Pear } & \multicolumn{2}{|c|}{ Apple } & \multicolumn{2}{|c|}{ Kiwifruit } & \multirow{2}{*}{$\begin{array}{c}\text { Expected } \\
\text { composition }\end{array}$} & \multirow{2}{*}{$\begin{array}{c}\text { Home-made } \\
\text { smoothie }\end{array}$} & \multirow{2}{*}{$\begin{array}{c}\text { Commercial } \\
\text { smoothie }\end{array}$} \\
\hline & Mean & SD & $\overline{\text { Mean }}$ & $\mathrm{SD}$ & Mean & $\mathrm{SD}$ & & & \\
\hline AOX capacity: FRAP $(\mu \mathrm{mol}$ TE/100 g) & 47.1 & 3.8 & 108 & 5.4 & 434 & 10.5 & $161+\dagger \dagger$ & 312 & $1374 * * *$ \\
\hline ORAC $(\mu \mathrm{mol} \mathrm{TE} / 100 \mathrm{~g})$ & 112 & 6.3 & 368 & 10.9 & 637 & 13.1 & $319+\dagger \dagger$ & 684 & $2254 * * *$ \\
\hline Vitamin $C(\mathrm{mg} / 100 \mathrm{~g})$ & 13.2 & 0.59 & 11.3 & 0.5 & 38.2 & 2.8 & 18.8 & 15.5 & $29.7 * * *$ \\
\hline Total phenolics (mg GAE/100 g) & 3.6 & 0.3 & 13 & 0.9 & 30.3 & 1.4 & $13.1+\dagger \dagger$ & 5.8 & $37.6 * * *$ \\
\hline$\beta$-Carotene $(\mu \mathrm{g} / 100 \mathrm{~g})$ & 17 & 0 & 15 & 0.02 & 36 & 1.6 & 22.8 & 19.1 & 20.1 \\
\hline Sugars $(\mathrm{mg} / 100 \mathrm{~g})$ & 9.4 & 0.2 & 10.3 & 0.5 & 9.9 & 0.4 & 9.8 & 9.0 & 9.0 \\
\hline
\end{tabular}

TE, Trolox equivalent; GAE, gallic acid equivalent. Mean values were significantly different from those for home-made: $* * * P<0.001$. Mean values were significantly different from those for home-made: $\dagger \uparrow \uparrow P<0.001$.

Sugars and $\beta$-carotene levels for both smoothies were as predicted. The home-made drink had the expected vitamin $\mathrm{C}$ content, whilst that of the commercial drink was much higher, reflecting the addition of $4 \mathrm{~g}$ ascorbic acid/l. The phenolic content of the commercial smoothie was much higher than expected $(P<0.001)$, which may reflect a greater efficiency of homogenisation in the manufacturing process. The commercial smoothie also contained the highest antioxidant capacity. Thus, smoothies, both home-made and commercial, appear to be beneficial in assisting compliance with the '5-a-day' recommendation.

1. Henderson L, Gregory J, Irving K et al. (2004) National Diet and Nutrition Survey: Adults Aged 19-64 Years. London: The Stationery Office.

2. Paskett Public Relations (2002) The freshly squeezed juice and smoothie report http://www.ohf.co.uk/reports/5_a_day.pdf.

3. Methods of Biochemical and Food Analysis, (1987) Boehringer Mannheim

4. Benzie IFF \& Strain JJ (1996) Anal Biochem 239, 70-76.

5. Huang D, Ou B, Hampsch-Woodill M et al. (2002) J Agric Food Chem 50, 4437-4444.

6. Forrest, G. I. \& Bendall, D. S. (1969). Journal of Biochemistry 113, 741-55. 